\title{
Pareto Improving Price Regulation when the Asset Market Is Incomplete
}

Citation for published version (APA):

Herings, P. J. J., \& Polemarchakis, H. M. (2003). Pareto Improving Price Regulation when the Asset Market Is Incomplete. Maastricht University School of Business and Economics. METEOR Research Memorandum No. 035 https://doi.org/10.26481/umamet.2003035

Document status and date:

Published: 01/01/2003

DOI:

10.26481/umamet.2003035

Document Version:

Publisher's PDF, also known as Version of record

\section{Please check the document version of this publication:}

- A submitted manuscript is the version of the article upon submission and before peer-review. There can be important differences between the submitted version and the official published version of record.

People interested in the research are advised to contact the author for the final version of the publication, or visit the DOI to the publisher's website.

- The final author version and the galley proof are versions of the publication after peer review.

- The final published version features the final layout of the paper including the volume, issue and page numbers.

Link to publication

\footnotetext{
General rights rights.

- You may freely distribute the URL identifying the publication in the public portal. please follow below link for the End User Agreement:

www.umlib.nl/taverne-license

Take down policy

If you believe that this document breaches copyright please contact us at:

repository@maastrichtuniversity.nl

providing details and we will investigate your claim.
}

Copyright and moral rights for the publications made accessible in the public portal are retained by the authors and/or other copyright owners and it is a condition of accessing publications that users recognise and abide by the legal requirements associated with these

- Users may download and print one copy of any publication from the public portal for the purpose of private study or research.

- You may not further distribute the material or use it for any profit-making activity or commercial gain

If the publication is distributed under the terms of Article $25 \mathrm{fa}$ of the Dutch Copyright Act, indicated by the "Taverne" license above, 


\title{
Pareto improving price regulation when the asset market is incomplete ${ }^{123}$
}

\author{
P.J.J. Herings ${ }^{4} \quad$ H. Polemarchakis ${ }^{5}$
}

May, 2003

\footnotetext{
${ }^{1}$ Earlier and longer versions were circulated as Discussion Paper No. 9841 (June, 1998), CORE, Université Catholique de Louvain, and Working Paper No. 01-31 (2001), Department of Economics, Brown University.

${ }^{2}$ The research of Herings was made possible by a fellowship of the Royal Netherlands Academy of Arts and Sciences and a grant of the Netherlands Organization for Scientific Research (NWO); while this paper was being written, he enjoyed the generous hospitality of the Cowles Foundation.

${ }^{3}$ John Geanakoplos and Hamid Sabourian asked questions that clarified a number of points in earlier drafts of the paper. Two anonymous referees and, in particular, an associate editor made comments that were insightful and helpful.

${ }^{4}$ Department of Economics, Universiteit Maastricht, P.O. Box 616, 6200 MD Maastricht, The Netherlands; e-mail: p.herings@algec.unimaas.nl

${ }^{5}$ Department of Economics, Brown University, Providence, R.I. 02912, USA; e-mail: herakles_polemarchakis@brown.edu
} 


\begin{abstract}
Incomplete asset markets cause competitive equilibria to be constrained suboptimal and provides scope for Pareto improving interventions. This paper examines how intervention in prices of spot market commodities may serve this purpose. We show that if fix-price equilibria behave sufficiently regular near Walrasian equilibria, Pareto improving price regulation is generically possible. We derive sufficient conditions for fix-price equilibria to be well-behaved in the neighborhood of a competitive equilibrium. An advantage of price regulation, contrasted with interventions in individuals' asset portfolios, is that it operates anonymously, on market variables.
\end{abstract}

Key words: incomplete asset market, fix-price equilibria, Pareto improvement.

JEL classification numbers: D45, D52, D60. 


\section{Introduction}

When asset markets are incomplete, competitive equilibrium allocations generically fail to satisfy the criterion of constrained Pareto optimality which recognizes the incompleteness of the asset market. Geanakoplos and Polemarchakis (1986) show that generically, there exist reallocations of portfolios that yield Pareto improvements in welfare after prices in spot commodity markets adjust to attain equilibrium. Citanna, Kajii and Villanacci (1998) developed and generalized the argument.

Expansions of the asset market do not necessarily lead to Pareto improvements: Hart (1975) gave an example of financial innovation that leads to a Pareto deterioration; Cass and Citanna (1998), Elul (1995) and Hara (1997) identified conditions for Pareto improving financial innovation. The failure of constrained optimality casts doubt on non-intervention with competitive markets.

The taxation of trades in assets, which is anonymous, can generically implement a Pareto improvement. Citanna, Polemarchakis and Tirelli (2001) demonstrated the result, which requires that the number of individuals not exceed the number of traded assets; it provides only a partial answer to Kajii (1994), who pointed out that, apart from informational requirements, the heterogeneity of individuals and the requirement of anonymity may interfere with improving interventions.

The direct regulation of prices in spot commodity markets is an alternative to the reallocation of portfolios or the taxation of trades in assets. Importantly, this is not an intervention in individual choice variables but in market variables, and, as such, it satisfies the requirement of anonymity.

An extension of the fix-price equilibrium of Drèze (1975) provides a notion of equilibrium that allows for trading at non-competitive prices; alternative specifications, in Barro and Grossman (1971), Bénassy (1975) or Younès (1975) should not affect the argument.

The results of Laroque $(1978,1981)$, nevertheless, provide a stumbling block: the behavior of fix-price equilibria in the neighborhood of competitive equilibria is particularly complicated. There are robust examples for which, at regulated prices close to competitive prices, there are no fix-price equilibria close to competitive equilibria. Here, we restrict attention to the class of economies, evidently restrictive, that satisfy conditions sufficient for the local uniqueness of fix-price equilibria. In Herings and Polemarchakis (2003), a robust example illustrates the approach as well as the results.

The conditions under which the result holds, that the number of instruments (contingent commodities) exceed the number of objectives (individuals), imply that the result complements the one of Geanakoplos and Polemarchakis (1986) and Citanna, Polemarchakis and Tirelli (2001).

Antecedents of this result are the argument in Polemarchakis (1979), where fixed wages that need not match shocks in productivity may yield higher expected utility in spite of the loss of output in an economy of overlapping generations; and the argument in Drèze and Gollier (1993), which employs the capital 
asset pricing model to determine optimal schedules of wages that differ from the marginal productivity of labor. Kalmus (1997) gave a heuristic example of Pareto improving price regulation.

Of serious concern are the informational requirements needed to determine, even compute, improving interventions. In the case of price regulation they involve knowledge of marginal utilities of income and excess demands for commodities across states. Geanakoplos and Polemarchakis (1990) and Kübler, Chiappori, Ekeland and Polemarchakis (2002) are only first steps towards an analysis of the informational requirements of active policy.

\section{The economy}

The economy is that of the standard two-period general equilibrium model with numéraire assets and incomplete asset markets. Assets exchange before and commodities after the state of the world realizes.

States of the world are $s \in \mathcal{S}=\{1, \ldots, S\}$ and commodities are $l \in \mathcal{L}=$ $\{1, \ldots, L+1\}$. At state $s$, commodity $(L+1, s)$ is numéraire. Assets are $a \in \mathcal{A}=$ $\{1, \ldots, A+1\}$. Asset $A+1$ is numéraire. The payoffs of assets are denominated in the numéraire commodity, $(L+1, s)$, at every state of the world.

A bundle of commodities at a state of the world is $x_{s}=\left(\ldots, x_{l, s}, \ldots\right.$, $\left.x_{(L+1), s}\right)$; across states of the world, $x=\left(\ldots, x_{s}, \ldots\right)$. A portfolio of assets is $y=\left(\ldots, y_{a}, \ldots, y_{A+1}\right)$.

The payoffs of an asset across states of the world are $R_{a}=\left(\ldots, R_{a, s}, \ldots\right)^{\prime}$; at a state of the world, payoffs of assets are $R_{. s}=\left(\ldots, R_{a, s}, \ldots\right)$; across states of the world, the asset payoff matrix is $R=\left(\ldots, R_{a}, \ldots\right)$.

The asset payoff matrix has full column rank, and the numéraire asset has positive payoffs: $R_{A+1}>0$.

Individuals are $i \in \mathcal{I}=\{1, \ldots, I\}$. A utility function, $u^{i}$, that satisfies standard conditions of continuity, monotonicity, quasi-concavity and, when required, smoothness and boundary behavior ${ }^{1}$, and the endowment, $e^{i}$, a strictly positive bundle, describe an individual.

The utility functions and consumption sets of individuals as well as the matrix of asset payoffs do not vary. The allocation of endowments, $\omega=\left(\ldots, e^{i}, \ldots\right)$, identifies an economy, and the set of economies coincides with the strictly positive orthant of the commodity space; a property holds generically if it holds for an open set of economies of full Lebesgue measure.

Prices of commodities at a state of the world are $\left(\ldots, p_{l, s}, \ldots, 1\right)$; across states of the world, $p=\left(\ldots, p_{s}, \ldots\right) \gg 0$; the price of the numéraire commodity at a state of the world is $p_{L+1, s}=1$; the domain of prices of commodities is $\mathcal{P}$. Prices of assets are $q=\left(\ldots, q_{a}, \ldots, 1\right)$; The price of the numéraire asset is $q_{A+1}=1$. The domain of prices of assets is $\mathcal{Q}$.

It is often convenient to truncate prices of commodities and prices of assets by deleting the prices of the numéraires. Commodities or assets other than the

\footnotetext{
${ }^{1}$ Boundary behavior guarantees consumption bundles to be chosen in the interior of the consumption set (see Debreu (1972))
} 
numéraire are $\breve{\mathcal{L}}$ or $\breve{\mathcal{A}}$; the domain of prices of commodities or assets other than the numéraires is $\breve{\mathcal{P}}$ or $\breve{\mathcal{Q}}$.

At arbitrary terms of trade, a competitive equilibrium, typically, does not exist. In commodities and assets other than the numéraire, rationing on net trades, uniform across individuals, serves to attain market clearing. Rationing in the supply (demand) of commodities other than the numéraire is $\underline{z} \leq 0$ $(\bar{z} \geq 0)$. Rationing in the supply (demand) of assets other than the numéraire is $\underline{y} \leq 0(\bar{y} \geq 0)$. Without appropriate rationing constraints, demand and supply of commodities will not match, which leads to inconsistencies. Equilibrium rationing constraints are exactly such that markets clear.

At prices and rationing $(p, q, \underline{z}, \bar{z}, \underline{y}, \bar{y})$, the budget set of an individual is

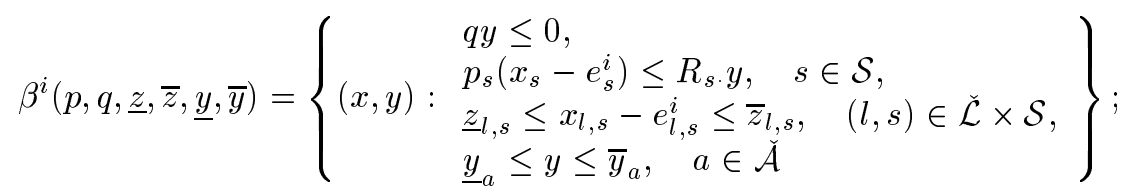

his optimization problem is to choose a utility maximizing consumption bundle and asset portfolio in his budget set. The set of all optimal consumption bundles and asset portfolios is denoted $d^{i}(p, q, \underline{z}, \bar{z}, y, \bar{y})$.

An individual is effectively rationed in his supply (demand) for a commodity or an asset if he could increase his utility when the rationing constraint in the supply (demand) of that commodity or asset is removed. There is effective supply (demand) rationing in the market for a commodity or an asset if at least one individual is effectively rationed in his supply (demand) for this commodity or asset. At a competitive equilibrium, there is neither effective supply rationing nor effective demand rationing in the market for any commodity or asset. In this sense, a competitive equilibrium is a special case of a fix-price equilibrium.

Definition 1 (Fix-price equilibrium). A fix-price equilibrium at prices $(p, q)$ is a pair $\left(\left(x^{*}, y^{*}\right),\left(\underline{z}^{*}, \bar{z}^{*}, \underline{y}^{*}, \bar{y}^{*}\right)\right)$, such that

1. for every individual, $\left(x^{i *}, y^{i *}\right) \in d^{i}\left(p, q, \underline{z}^{*}, \bar{z}^{*}, \underline{y}^{*}, \bar{y}^{*}\right)$,

2. $\sum_{i=1}^{I} x^{i *}=\sum_{i=1}^{I} e^{i}$ and $\sum_{i=1}^{I} y^{i *}=0$,

3. for every $l \in \check{\mathcal{L}}$, if for some $i^{\prime} x_{l, s}^{i^{\prime} *}-e_{l, s}^{i^{\prime}}=\underline{z}_{l, s}^{*}$, then for all $i \in \mathcal{I} x_{l, s}^{i *}-e_{l, s}^{i}<$ $\bar{z}_{l, s}^{*}$, while if for some $i^{\prime} x_{l, s}^{i^{\prime} *}-e_{l, s}^{i^{\prime}}=\bar{z}_{l, s}^{*}$, then for all $i \in \mathcal{I} x_{l, s}^{i *}-e_{l, s}^{i}>\underline{z}_{l, s}^{*}$,

4. for every $a \in \check{\mathcal{A}}$, if for some $i^{\prime} y_{a}^{i^{\prime} *}=\underline{y}_{a}^{*}$, then for all $i \in \mathcal{I} y_{a}^{i *}<\bar{y}_{a}^{*}$, while if for some $i^{\prime} y_{a}^{i^{*} *}=\bar{y}_{a}^{*}$, then for all $i \in \mathcal{I} y_{a}^{i *}>\underline{y}_{a}^{*}$.

At a fix-price equilibrium, only one side of the market is effectively rationed. This is expressed by Conditions 3 and 4 .

At prices $(p, q)$, fix-price equilibria exist. Appendix 1 spells out the arguments in detail. Herings and Polemarchakis (2002) provide a (more complicated) proof that requires weaker assumptions on the primitives. 
A sign vector,

$$
r=\left(r_{1,1}, \ldots, r_{L, S}, r_{1}, \ldots, r_{A}\right),
$$

describes the state of markets at a fix-price equilibrium. If there is effective supply rationing in the market for a commodity or an asset, the associated component of the sign vector is -1 , if there is effective demand rationing it is +1 , and if there is no effective rationing it is 0 .

For a sign vector $r$, the set $\mathcal{P} \mathcal{Q}(r)$ is the set of prices $(p, q) \in \mathcal{P} \times \mathcal{Q}$, for which there exists a fix-price equilibrium at prices $(p, q)$ with state of the markets $r$. For prices $(p, q) \in \mathcal{P} \times \mathcal{Q}$, the set of fix-price equilibrium allocations is $\mathcal{D}(p, q)$, and, for a sign vector $r$, the set of fix-price equilibrium allocations with state of the markets $r$ is $\mathcal{D}(p, q, r)$.

A neighborhood of $\alpha$ is $\mathcal{N}_{\alpha}$. If $\left(\left(p^{*}, q^{*}\right),\left(x^{*}, y^{*}\right)\right)$ is a competitive equilibrium, the allocation $\left(x^{*}, y^{*}\right)$ is locally unique as a fix-price equilibrium allocation if there exists a neighborhood $\overline{\mathcal{N}}_{x^{*}, y^{*}}$ such that for every $\mathcal{N}_{x^{*}, y^{*}} \subset \overline{\mathcal{N}}_{x^{*}, y^{*}}$ there exists a neighborhood $\mathcal{N}_{p^{*}, q^{*}}$ with $\mathcal{D}(p, q) \cap \mathcal{N}_{x^{*}, y^{*}}$ a singleton for every $(p, q) \in \mathcal{N}_{p^{*}, q^{*}}$.

If a competitive equilibrium allocation is locally unique as a fix-price equilibrium allocation, then, for prices close to competitive equilibrium prices, there is exactly one fix-price equilibrium allocation close to the competitive allocation.

For a locally unique competitive equilibrium allocation, for each sign vector $r$, the function $\left(\widehat{x}^{r}, \widehat{y}^{r}\right): \overline{\mathcal{N}}_{p^{*}, q^{*}} \cap \mathcal{P} \mathcal{Q}(r) \rightarrow \mathbb{R}^{I(L+1) S+I(A+1)}$ associates the unique fix-price equilibrium allocation in $\overline{\mathcal{N}}_{x^{*}, y^{*}} \cap \mathcal{D}(p, q, r)$ to $(p, q)$.

Comparative statics require a differentiable form of local uniqueness.

Definition 2 (Differentiable local uniqueness). If $\left(\left(p^{*}, q^{*}\right),\left(x^{*}, y^{*}\right)\right)$ is a competitive equilibrium, the allocation $\left(x^{*}, y^{*}\right)$ is differentiably locally unique as a fix-price equilibrium allocation if it is locally unique and there is a neighborhood $\mathcal{N}_{p^{*}, q^{*}}$ such that, for every sign vector $r$, the function $\left(\widehat{x}^{r}, \widehat{y}^{r}\right)_{\mid \mathcal{N}_{p^{*}, q^{*}} \cap}$ $\mathcal{P Q}(r)$ is differentiable.

Laroque and Polemarchakis (1978) proved, for a complete asset market, that, generically, the set of fix-price equilibrium allocations can be represented by a finite number of continuously differentiable functions of prices. Nevertheless, the results in Laroque (1978) and the examples in Madden (1982) show that competitive equilibria need not be locally unique as fix-price equilibria. Even though fix-price equilibrium allocations exist for all prices, there may be robust local non-existence, and therefore local non-uniqueness as a fix-price equilibrium, at competitive prices.

Assumption 1. For endowments in $\Omega^{*}$, an open set of full Lebesgue measure, if $\left(\left(p^{*}, q^{*}\right),\left(x^{*}, y^{*}\right)\right)$ is a competitive equilibrium, then the competitive equilibrium allocation is differentiably locally unique as a fix-price equilibrium allocation.

By an argument similar to the one in the proof of Theorem 1, Laroque (1981), Appendix 2 characterizes economies where competitive equilibrium allocation are differentiably locally unique as a fix-price equilibrium allocation. 
Local uniqueness of fix-price equilibrium allocations at competitive equilibria is not too strong a requirement; it is less demanding than the requirement of uniqueness of fix-price equilibrium allocations at prices in a neighborhood of competitive prices. This guarantees a certain degree of generality of the results.

The function $(\widehat{x}, \widehat{y})$ associates the unique fix-price equilibrium allocation in $\mathcal{N}_{x^{*}, y^{*}}$ to $(p, q) \in \mathcal{N}_{p^{*}, q^{*}}$. At a locally unique fix-price equilibrium,

$$
v^{i}(p, q)=u^{i}\left(\widehat{x}^{i}(p, q)\right), \quad(p, q) \in \mathcal{N}_{p^{*}, q^{*}}
$$

defines the indirect utility function of an individual. Lemma 2 in Appendix 2 implies that it is differentiable when the fix-price equilibrium is differentiably locally unique, with partial derivatives given by

$$
\partial_{p_{l, s}} v^{i}\left(p^{*}, q^{*}\right)=-\partial_{x_{L+1, s}} u^{i}\left(x^{i *}\right)\left(x_{l, s}^{i *}-e_{l, s}^{i}\right), \quad(l, s) \in \check{\mathcal{L}} \times \mathcal{S} .
$$

The effect of a change in the spot market price of commodity $(l, s) \in \check{\mathcal{L}} \times \mathcal{S}$ is equal to minus the marginal utility of the numéraire commodity in state $s$ multiplied by the excess demand of commodity $(l, s)$ at the competitive equilibrium. Lemma 2 in Appendix 2 therefore implies that the indirect welfare effects of a change in prices, generated by the induced change in the rationing constraints and individuals' choices, equal zero.

\section{Pareto improving price regulation}

If the asset market is incomplete, $A+1<S$, generically, competitive equilibrium allocations are not Pareto optimal.

Price regulation can Pareto improve on a competitive equilibrium $\left(\left(p^{*}\right.\right.$, $\left.\left.q^{*}\right),\left(x^{*}, y^{*}\right)\right)$ if there exist prices of commodities $p$ such that a fix-price equilibrium of commodities at prices of commodities and assets $\left(p, q^{*}\right)$ Pareto dominates the allocation $x^{*}$. The ambiguity introduced by the possibility of multiple fix-price equilibrium allocations at prices $\left(p, q^{*}\right)$ is circumvented by considering local variations at competitive equilibrium allocations that are differentiably locally unique as fix-price equilibria.

Definition 3 (Pareto improving price regulation). Price regulation can Pareto improve upon a competitive equilibrium, $\left(\left(p^{*}, q^{*}\right),\left(x^{*}, y^{*}\right)\right)$, that is locally unique as a fix-price equilibrium if there exists $d \check{p} \in \mathbb{R}^{L S}$ such that $\sum_{(l, s) \in \check{\mathcal{L}} \times \mathcal{S}} \partial_{p_{l, s}} v^{i}\left(p^{*}, q^{*}\right) d p_{l, s}>0, i \in \mathcal{I}$.

Uniform price regulation can improve upon a competitive equilibrium if $d \check{p}_{s}=$ $d \check{p}_{s^{\prime}}, s, s^{\prime} \in \mathcal{S}$.

If (uniform) price regulation can improve upon a competitive equilibrium, there is $\bar{\varepsilon}>0$ such that for all $\varepsilon \in(0, \bar{\varepsilon}]$, the fix-price equilibrium in the neighborhood of the competitive equilibrium $\left(\left(p^{*}, q^{*}\right),\left(x^{*}, y^{*}\right)\right)$ at commodity prices $\check{p}^{*}+\varepsilon d \check{p}$ and asset prices $q^{*}$ Pareto dominates the competitive equilibrium. Uniform price regulations are of interest because they imply a state-independent change in prices. It shows that relatively simple policies suffice for the realization of a Pareto improvement. 
Generically, it is possible to make every individual better off by choosing appropriate price regulations on the spot markets when asset markets are incomplete. One needs at least as many instruments, $L S$, as individuals, $I$.

Uniform price regulation is effective when $L \geq I$, which reflects again that the number of instruments has to exceed the number of objectives. This complements the constrained suboptimality result of Geanakoplos and Polemarchakis (1986), which applies when $2 L \leq I \leq L(S-1)+1$.

Proposition 1. Suppose:

1. For every individual, the consumption set is $\mathcal{X}^{i}=\{x: x \geq 0\}$; the utility function is continuous and quasi - concave; in the interior of the consumption set ${ }^{2}$, Int $\mathcal{X}^{i}$, it is twice continuously differentiable, $\partial u^{i} \gg 0$ and $\partial^{2} u^{i}$ is negative definite on ${ }^{3}\left(\partial u^{i}\right)^{\perp}$; the endowment is strictly positive: $e^{i} \in \operatorname{Int} \mathcal{X}^{i}$, and $u^{i}\left(e^{i}\right)>u^{i}(x)$, for every $x \in \operatorname{Bd} \mathcal{X}^{i}$.

2. The matrix of payoffs of assets has full column rank. The numeraire asset, has positive payoff: $r_{A+1}>0$.

If Assumption 1 holds, the asset market is incomplete $(A+1<S)$, and if $L S \geq I>1$, then, generically, price regulation can improve upon any competitive equilibrium. If $L \geq I>1$, then, generically, uniform price regulation can improve upon any competitive equilibrium.

Appendix 3 gives the proof, which follows Geanakoplos and Polemarchakis (1986) and Citanna, Kajii and Villanacci (1998).

In the paper we focus on the adjustment of prices of state-contingent commodities, rather than asset prices. One reason for this is that government interventions in commodity prices seem to occur much more frequently than government control of asset prices. From a purely normative point of view, the case where the central planner is limited to adjustments of asset prices only, with competitive spot commodity markets in future periods, is interesting as well. It provides an anonymous alternative to the adjustment of individual asset portfolios as proposed in Geanakoplos and Polemarchakis (1986).

A final issue of interest is the case where asset prices adjust to clear markets after the central planner intervened in spot commodity markets. The current analysis fixes asset prices at $q^{*}$, which allows us to derive a simple expression for the derivative with respect to spot commodity prices of the indirect utility function in Lemma 2. The corresponding expression for an indirect utility function where asset prices adjust to clear the asset markets is more complicated, and the question whether Pareto improving price regulation is possible in that sense is open.

\footnotetext{
2 "Int" denotes the interior of a set and "Bd" the boundary.

3 " $\perp$ " denotes the orthogonal complement.
} 


\section{References}

1. Barro, R. J. and H. I. Grossman (1971), "A general disequilibrium model of income and employment," American Economic Review, 61, 82-93.

2. Bénassy, J.-P. (1975), "Neokeynesian disequilibrium theory in a monetary economy," Review of Economic Studies, 42, 503-523.

3. Cass, D., and A. Citanna (1998), "Pareto improving financial innovation in incomplete markets," Economic Theory, 11, 467-494.

4. Citanna, A., A. Kajii and A. Villanacci (1998), "Constrained suboptimality in incomplete markets: a general approach and two applications," Economic Theory, 11, 495-522.

5. Citanna, A., H. Polemarchakis and M. Tirelli (2001), "The taxation of trades in assets,"Working Paper No. 2001-21, Department of Economics, Brown University.

6. Debreu, G. (1972), "Smooth Preferences," Econometrica, 40, 603-615.

7. Drèze, J. H. (1975), "Existence of an exchange equilibrium under price rigidities," International Economic Review, 16, 301-320.

8. Drèze, J. H., and C. Gollier (1993), "Risk sharing on the labour market," European Economic Review, 37, 1457-1482.

9. Elul, R. (1995), "Welfare effects of financial innovation in a general equilibrium model," Journal of Economic Theory, 65, 43-78.

10. Geanakoplos, J. D. and H. M. Polemarchakis (1986), "Existence, regularity, and constrained suboptimality of competitive allocations when the asset market is incomplete," in W. P. Heller, R. M. Starr and D. A. Starrett (eds.), Uncertainty, Information and Communication: Essays in Honor of K. J. Arrow, Vol. III, Cambridge University Press, 65-96.

11. Geanakoplos, J. D. and H. M. Polemarchakis (1990), "Observability and optimality," Journal of Mathematical Economics, 19, 153-165.

12. Hara, C. (1997), "A sequence of Pareto improving financial innovations," mimeo.

13. Hart, O. D. (1975), "On the optimality of equilibrium when the market structure is incomplete," Journal of Economic Theory, 11, 418-443.

14. Herings, P. J. J. and H. M. Polemarchakis (1998), "Pareto improving price regulation when the asset market is incomplete," Discussion Paper No. 9841, CORE, Université Catholique de Louvain; revised as Working Paper No. 01-31 (2001), Department of Economics, Brown University, (2001). 
15. Herings, P.J.J., and H.M. Polemarchakis (2002), "Equilibrium and Arbitrage in Incomplete Asset Markets with Fixed Prices," Journal of Mathematical Economics, 37, 133-155.

16. Herings, P. J. J. and H. M. Polemarchakis (2003), "Pareto improving price regulation when the asset market is incomplete: an example," mimeo.

17. Kajii, A. (1994), "Anonymity and optimality of competitive equilibria when assets are incomplete," Journal of Economic Theory, 64, 115-129.

18. Kalmus, P. (1997), "Pareto improving trade restrictions: an example,"mimeo.

19. Kübler, F., Chiappori, P.-A., I. Ekeland and H. M. Polemarchakis (2002), "The identification of preferences from the equilibrium prices under uncertainty," Journal of Economic Theory, 102, 403-420.

20. Laroque, G. (1978), "The fixed price equilibria: some results in local comparative statics," Econometrica, 46, 1127-1154.

21. Laroque, G. (1981), "On the local uniqueness of the fixed price equilibria," Review of Economic Studies, 48, 113-129.

22. Laroque, G. and H. M. Polemarchakis (1978), "On the structure of the set of fixed price equilibria," Journal of Mathematical Economics, 5, 53-69.

23. Madden, P. (1982), "Catastrophic Walrasian equilibrium from the nonWalrasian viewpoint: A three-good macroeconomic example," Review of Economic Studies, 49, 661-667.

24. Polemarchakis, H. M. (1979), "Incomplete markets, price regulation, and welfare," American Economic Review, 69, 662-669.

25. Younès, Y. (1975), "On the role of money in the process of exchange and the existence of a non-Walrasian equilibrium," Review of Economic Studies, 42, 489-501. 


\section{Appendix 1: existence of fix-price equilibria}

A compact, convex subset of the consumption set that contains the aggregate initial endowment in its interior is $\widetilde{\mathcal{X}}^{i}$ The assumptions on utility functions and on the asset return matrix imply that all $S+1$ budget inequalities in the definition of the budget set hold with equality at the optimal choice of an individual. The rationing inequalities do not necessarily hold with equality. The budget set related to $\widetilde{\mathcal{X}}^{i}$ with all budget inequalities required to hold with equality is $\widetilde{\beta}^{i}$ and the corresponding demand function $\widetilde{d}^{i}$. Since prices are fixed at $(p, q)$, they are omitted in the notation.

The demand functions $\widetilde{d}^{i}, i \in \mathcal{I}$, are continuous.

If $\left(\underline{z}_{n}, \bar{z}_{n}, \underline{y}_{n}, \bar{y}_{n}\right)$ is a sequence that converges to $(\underline{z}, \bar{z}, \underline{y}, \bar{y})$, then the sequence $\left(\widetilde{d}^{i}\left(\underline{z}_{n}, \bar{z}_{n}, \underline{y}_{n}, \bar{y}_{n}\right)\right)$ has a convergent subsequence, with limit $(\widehat{x}, \widehat{y}) \in$ $\widetilde{\beta}^{i}(\underline{z}, \bar{z}, \underline{y}, \bar{y})$.

If there exists $(\widetilde{x}, \widetilde{y}) \in \widetilde{\beta}^{i}(\underline{z}, \bar{z}, \underline{y}, \bar{y})$, such that $u^{i}(\widetilde{x})>u^{i}(\widehat{x})$, and $\widetilde{\mathcal{L}}_{-}, \widetilde{\mathcal{L}}_{+}$, $\widetilde{\mathcal{A}}_{-}$, and $\widetilde{\mathcal{A}}_{+}$, is the sets of non-numéraire commodities and non-numéraire assets for which $\widetilde{x}_{l, s}-e_{l, s}^{i}$ is negative, positive, $\widetilde{y}_{a}$ is negative, and positive, respectively, then, for

$$
\begin{aligned}
& \lambda^{n}= \\
& \min \left\{1, \frac{\underline{z}_{l, s}^{n}}{\widetilde{x}_{l, s}-e_{l, s}^{i}},(l, s) \in \widetilde{\mathcal{L}}_{-}, \frac{\bar{z}_{l, s}^{n}}{\bar{x}_{l, s}-e_{l, s}^{i}},(l, s) \in \widetilde{\mathcal{L}}_{+}, \frac{\underline{y}_{a}^{n}}{\bar{y}_{a}}, a \in \widetilde{\mathcal{A}}_{-}, \frac{\bar{y}_{a}^{n}}{\bar{y}_{a}}, a \in \widetilde{\mathcal{A}}_{+}\right\}, \\
& \widetilde{x}^{n}=e^{i}+\lambda^{n}\left(\widetilde{x}-e^{i}\right) \text {, and } \widetilde{y}^{n}=\lambda^{n} \widetilde{y},\left(\widetilde{x}^{n}, \widetilde{y}^{n}\right) \in \widetilde{\beta}^{i}\left(\underline{z}^{n}, \bar{z}^{n}, \underline{y}^{n}, \bar{y}^{n}\right) \text {. Evidently, } \\
& \lim _{n \rightarrow \infty} \lambda^{n}=1 \text {, and } \lim _{n \rightarrow \infty}\left(\widetilde{x}^{n}, \widetilde{y}^{n}\right)=(\widetilde{x}, \widetilde{y}) \text {. By the continuity of } u^{i}, \widetilde{x}^{n} \text { is } \\
& \text { strictly preferred to the consumption bundle in } \widetilde{d}^{i}\left(\underline{z}_{n}, \bar{z}_{n}, \underline{y}_{n}, \bar{y}_{n}\right) \text {, a contradic- } \\
& \underline{z}_{l, s}(r)=-\min \left\{2 r_{l, s}\left(\sum_{i=1}^{I} e_{l, s}^{i}+\varepsilon\right), \sum_{i=1}^{I} e_{l, s}^{i}+\varepsilon\right\}, \quad(l, s) \in \check{\mathcal{L}} \times \mathcal{S}, \\
& \bar{z}_{l, s}(r)=\min \left\{\left(2-2 r_{l, s}\right)\left(\sum_{i=1}^{I} e_{l, s}^{i}+\varepsilon\right), \sum_{i=1}^{I} e_{l, s}^{i}+\varepsilon\right\}, \quad(l, s) \in \breve{\mathcal{L}} \times \mathcal{S}, \\
& \underline{y}_{a}(\rho)=-\min \left\{2 \rho_{a} \alpha, \alpha\right\}, \quad a \in \check{\mathcal{A}}, \\
& \bar{y}_{a}(\rho)=\min \left\{\left(2-2 \rho_{a}\right) \alpha, \alpha\right\}, \quad a \in \check{\mathcal{A}} .
\end{aligned}
$$


The excess demand function $\widetilde{z}: \mathcal{C}^{L S} \times \mathcal{C}^{A} \rightarrow \mathbb{R}^{L S} \times \mathbb{R}^{A}$ is

$$
\begin{aligned}
& \widetilde{z}_{l, s}(r, \rho)=\sum_{i=1}^{I} \widetilde{d}_{l, s}^{i}(\underline{z}(r), \bar{z}(r), \underline{y}(\rho), \bar{y}(\rho))-\sum_{i=1}^{I} e_{l, s}^{i}, \quad(l, s) \in \check{\mathcal{L}} \times S \\
& \widetilde{z}_{a}(r, \rho)=\sum_{i=1}^{I} \widetilde{d}_{a}^{i}(\underline{z}(r), \bar{z}(r), \underline{y}(\rho), \bar{y}(\rho)), \quad a \in \check{\mathcal{A}} .
\end{aligned}
$$

If $\left(r^{*}, \rho^{*}\right) \in \mathcal{C}^{L S} \times \mathcal{C}^{A}$ is such that $\widetilde{z}\left(r^{*}, \rho^{*}\right)=0$, then $\left(\left(x^{*}, y^{*}\right),\left(\underline{z}^{*}, \bar{z}^{*}, \underline{y}^{*}\right.\right.$, $\left.\left.\bar{y}^{*}\right)\right)$, where $\left(x^{* i}, y^{* i}\right)=\widetilde{d}^{i}\left(\underline{z}^{*}, \bar{z}^{*}, \underline{y}^{*}, \bar{y}^{*}\right), i \in \mathcal{I},\left(\underline{z}^{*}, \bar{z}^{*}\right)=\left(\underline{z}\left(r^{*}\right), \bar{z}\left(r^{*}\right)\right),\left(\underline{y}^{*}, \bar{y}^{*}\right)$ $=\left(\underline{y}\left(r^{*}\right), \bar{y}\left(r^{*}\right)\right)$, is a fix-price equilibrium. Conditions 1 and 2 of Definition 1 are satisfied for non-numeraire commodities and assets. The construction of the functions $(\underline{z}, \bar{z})$ and $(\underline{y}, \bar{y})$ takes care of Conditions 3 and 4 .

The set $\widetilde{z}\left(\mathcal{C}^{L S} \times \overline{\mathcal{C}}^{A}\right)$ is compact. Let the set $\mathcal{Z} \mathcal{Y}$ be a compact, convex set that contains $\widetilde{z}\left(\mathcal{C}^{L S} \times \mathcal{C}^{A}\right)$. The correspondence $\mu: \mathcal{Z Y} \rightarrow \mathcal{C}^{L S} \times \mathcal{C}^{A}$ is defined by

$$
\mu(z, y)=\arg \max \left\{\sum_{(l, s) \in \check{\mathcal{L}} \times \mathcal{S}} r_{l, s} z_{l, s}+\sum_{a \in \breve{\mathcal{A}}} \rho_{a} y_{a}: r \in \mathcal{C}^{L S}, \rho \in \mathcal{C}^{A}\right\} .
$$

The correspondence $\varphi: \mathcal{Z} \mathcal{Y} \times \mathcal{C}^{L S} \times \mathcal{C}^{A} \rightarrow \mathcal{Z} \mathcal{Y} \times \mathcal{C}^{L S} \times \mathcal{C}^{A}$ is defined by $\varphi(z, y, r, \rho)=\{\widetilde{z}(r, \rho)\} \times \mu(z, y)$. It is a non-empty, compact, convex valued, upper hemi-continuous correspondence defined on a non-empty, compact, convex set. By Kakutani's fixed point theorem, $\varphi$ has a fixed point, $\left(z^{*}, y^{*}, r^{*}, \rho^{*}\right)$.

If, for some $a \in \check{\mathcal{A}}, y_{a}^{*}<0$, then, by the definition of $\mu, \rho_{a}^{*}=0$, so $y_{a}^{*} \geq 0$, a contradiction. If, for some $a \in \breve{\mathcal{A}}, y_{a}^{*}>0$, then, by the definition of $\mu, \rho_{a}^{*}=1$, so $y_{a}^{*} \leq 0$, a contradiction. Consequently, $y_{a}^{*}=0$, for all $a \in \check{\mathcal{A}}$. Moreover, $y_{A+1}^{*}=-\sum_{a \in \check{\mathcal{A}}} q_{a} y_{a}^{*}=0$.

If, for some $(l, s) \in \breve{\mathcal{L}} \times \mathcal{S}, z_{l, s}^{*}<0$, then, by the definition of $\mu, r_{l, s}^{*}=0$, so $z_{l, s}^{*} \geq 0$, a contradiction. If, for some $(l, s) \in \check{\mathcal{L}} \times \mathcal{S}, z_{l, s}^{*}>0$, then, by the definition of $\mu, r_{l, s}^{*}=1$, so $z_{l, s}^{*} \leq 0$, a contradiction. Consequently, $z_{l, s}^{*}=0$, for all $(l, s) \in \breve{\mathcal{L}} \times \mathcal{S}$. Moreover, for every $s \in \mathcal{S}, z_{L+1, s}^{*}=-\sum_{(l, s) \in \check{\mathcal{L}} \times \mathcal{S}} p_{l, s} z_{l, s}^{*}+$ $R_{s} \cdot y^{*}=0$.

It follows that $0 \in \widetilde{z}\left(r^{*}, \rho^{*}\right)$, so a fix-price equilibrium at prices $(p, q)$ exists.

\section{Appendix 2: local comparative statics}

In the optimization problem an individual faces when determining his demand, the Lagrange multipliers corresponding to the rationing constraints in the markets for commodities (assets) are $\pi(\rho)$. The individual optimization problem leads to the study of a modified demand function, $\widehat{d}^{i}$. At prices and Lagrange multipliers $(p, q, \pi, \rho), \widehat{d}^{i}$ is defined by the solution to the optimization problem

$$
\begin{array}{ll}
\max & u^{i}(x)-\sum_{(l, s) \in \check{\mathcal{L}} \times \mathcal{S}} \pi_{l, s} x_{l, s}-\sum_{a \in \check{\mathcal{A}}} \rho_{a} y_{a}, \\
\text { s.t. } & q y \leq 0 \\
& p_{s}\left(x_{s}-e_{s}^{i}\right) \leq R_{s} . y, \quad s \in \mathcal{S} .
\end{array}
$$


The set of $(p, q, \pi, \rho)$ on which each individual optimization problem has a solution is $\mathcal{N}$. Whenever $\left(p^{*}, q^{*}\right)$ are competitive equilibrium prices, $\mathcal{N}$ is a neighborhood of $\left(p^{*}, q^{*}, 0,0\right)$. $\mathcal{N}$.

The modified demand function, $\widehat{d}^{i}, i \in \mathcal{I}$, is continuously differentiable on At a competitive equilibrium, $\left(\left(p^{*}, q^{*}\right),\left(x^{*}, y^{*}\right)\right), z_{l, s}^{-}, z_{l, s}^{+}, y_{a}^{-}$and $y_{a}^{+}$, defined by

$$
\begin{array}{lll}
z_{l, s}^{-}=\min _{i \in \mathcal{I}} x_{l, s}^{i *}-e_{l, s}^{i}, & z_{l, s}^{+}=\max _{i \in \mathcal{I}} x_{l, s}^{i *}-e_{l, s}^{i}, & (l, s) \in \check{\mathcal{L}} \times \mathcal{S}, \\
y_{a}^{-}=\min _{i \in \mathcal{I}} y_{a}^{i *}, & y_{a}^{+}=\max _{i \in \mathcal{I}} y_{a}^{i *}, & a \in \check{\mathcal{A}},
\end{array}
$$

determine the minimal and the maximal excess demands on both the spot and the asset markets. If

$$
\begin{array}{ll}
\underline{\mathcal{I}}_{l, s}=\left\{i \in \mathcal{I}: x_{l, s}^{i *}-e_{l, s}^{i}=z_{l, s}^{-}\right\}, & (l, s) \in \check{\mathcal{L}} \times \mathcal{S}, \\
\overline{\mathcal{I}}_{l, s}=\left\{i \in \mathcal{I}: x_{l, s}^{i *}-e_{l, s}^{i}=z_{l, s}^{+}\right\}, & (l, s) \in \check{\mathcal{L}} \times \mathcal{S}, \\
\underline{\mathcal{I}}_{a}=\left\{i \in \mathcal{I}: y_{a}^{i *}=y_{a}^{-}\right\}, & a \in \check{\mathcal{A}}, \\
\overline{\mathcal{I}}_{a}=\left\{i \in \mathcal{I}: y_{a}^{i *}=y_{a}^{+}\right\}, & a \in \check{\mathcal{A}},
\end{array}
$$

then, in a neighborhood of the competitive equilibrium, only individuals in $\underline{\mathcal{I}}_{l, s}$ $\left(\overline{\mathcal{I}}_{l, s}\right)$ may be rationed on supply (demand) in the spot market $(l, s)$, and only individuals in $\underline{\mathcal{I}}_{a}\left(\overline{\mathcal{I}}_{a}\right)$ on supply (demand) in the asset market $a$.

For an open set of endowments with full Lebesgue measure $\Omega \subset \mathbb{R}_{++}^{I(L+1) S}$, for any competitive equilibrium $\left(\left(p^{*}, q^{*}\right),\left(x^{*}, y^{*}\right)\right)$ of $\mathcal{E},\left|\underline{\mathcal{I}}_{l, s}\right|=\left|\overline{\mathcal{I}}_{l, s}\right|=1$, $(l, s) \in \check{\mathcal{L}} \times \mathcal{S}$, and $\left|\underline{\mathcal{I}}_{a}\right|=\left|\overline{\mathcal{I}}_{a}\right|=1, a \in \check{\mathcal{A}}$.

For a generic set of economies, there is exactly one individual in each market with the minimal excess demand and exactly one individual with the maximal excess demand. For the remainder, the allocation of endowments in the economy $\mathcal{E}$ belong to the set $\Omega$, which permits the study of the local structure of the set fix-price equilibria in the neighborhood of a competitive equilibrium $\left(\left(p^{*}, q^{*}\right),\left(x^{*}, y^{*}\right)\right)$ of $\mathcal{E}$.

For every individual, the function $c^{i}: \mathbb{R}^{L S} \times \mathbb{R}^{A} \rightarrow \mathbb{R}^{L S} \times \mathbb{R}^{A}$ is defined by

$$
\begin{aligned}
& c_{l, s}^{i}(\pi, \rho)= \begin{cases}\pi_{l, s}, & \text { if } \pi_{l, s} \leq 0 \text { and }\{i\}=\underline{\mathcal{I}}_{l, s} \\
& \text { or } \pi_{l, s} \geq 0 \text { and }\{i\}=\overline{\mathcal{I}}_{l, s}, \\
0, & \text { otherwise, }\end{cases} \\
& c_{a}^{i}(\pi, \rho)=\left\{\begin{array}{cl}
\rho_{a}, & \text { if } \rho_{a} \leq 0 \text { and }\{i\}=\underline{\mathcal{I}}_{a} \\
& \text { or } \rho_{a} \geq 0 \text { and }\{i\}=\overline{\mathcal{I}}_{a}, \\
0, & \text { otherwise. }
\end{array}\right.
\end{aligned}
$$


The function $c$ associates with Lagrange multipliers, $(\pi, \rho)$, fix-price equilibria in the neighborhood of the competitive equilibrium. The aggregate modified excess demand function for commodities and assets other than the numéraire is $\widehat{z}: \mathcal{N} \rightarrow \mathbb{R}^{L S+A}$ defined by

$$
\begin{aligned}
& \widehat{z}_{l, s}(p, q, \pi, \rho)=\sum_{i \in \mathcal{I}} \widehat{d}_{l, s}^{i}\left(p, q, c^{i}(\pi, \rho)\right)-\sum_{i \in \mathcal{I}} e^{i}, \quad(l, s) \in \check{\mathcal{L}} \times \mathcal{S}, \\
& \widehat{z}_{a}(p, q, \pi, \rho)=\sum_{i \in \mathcal{I}} \widehat{d}_{a}^{i}\left(p, q, c^{i}(\pi, \rho)\right), \quad a \in \check{\mathcal{A}} .
\end{aligned}
$$

For the study of fix-price equilibria in the neighborhood of the competitive equilibrium, it is sufficient to restrict attention to the zero points of $\widehat{z}$. Neighborhoods $\mathcal{N}_{x^{i *}, y^{i *}}^{i}$ are such that, for every $(x, y) \in \mathcal{N}_{x^{*}, y^{*}}=\times_{i \in \mathcal{I}} \mathcal{N}_{x^{i *}, y^{i *}}^{i}$, for all $(l, s) \in \check{\mathcal{L}} \times \mathcal{S}$, for all $a \in \check{\mathcal{A}}$,

$$
\begin{array}{lr}
x_{l, s}^{i^{\prime}}-e_{l, s}^{i^{\prime}}<0 \text { and } x_{l, s}^{i^{\prime}}-e_{l, s}^{i^{\prime}}<x_{l, s}^{i}-e_{l, s}^{i}, & i \neq i^{\prime}, i^{\prime} \in \underline{\mathcal{I}}_{l, s} \\
x_{l, s}^{i^{\prime}}-e_{l, s}^{i^{\prime}}>0 \text { and } x_{l, s}^{i^{\prime}}-e_{l, s}^{i^{\prime}}>x_{l, s}^{i}-e_{l, s}^{i}, & i \neq i^{\prime}, i^{\prime} \in \overline{\mathcal{I}}_{l, s} \\
y_{a}^{i^{\prime}}<0 \text { and } y_{a}^{i^{\prime}}<y_{a}^{i}, & i \neq i^{\prime}, i^{\prime} \in \underline{\mathcal{I}}_{a} \\
y_{a}^{i^{\prime}}>0 \text { and } y_{a}^{i^{\prime}}>y_{a}^{i}, & i \neq i^{\prime}, i^{\prime} \in \overline{\mathcal{I}}_{a} .
\end{array}
$$

If $\left(\left(p^{*}, q^{*}\right),\left(x^{*}, y^{*}\right)\right)$ is a competitive equilibrium, and $(x, y) \in \mathcal{N}_{x^{*}, y^{*}}$, then $(x, y) \in \mathcal{D}(p, q)$ if and only if there is $(p, q, \pi, \rho) \in \mathcal{N}$ such that $\widehat{d}^{i}\left(p, q, c^{i}(\pi, \rho)\right)$ $=\left(x^{i}, y^{i}\right), i \in \mathcal{I}$, and $\widehat{z}(p, q, \pi, \rho)=(0,0)$.

The function $\widehat{z}$ is Lipschitz continuous because of the differentiability of the functions $\widehat{d}^{i}$ and the Lipschitz continuity of the functions $c^{i}$. It is differentiable at each $(p, q, \pi, \rho) \in \mathcal{N}$ where all components of $\pi$ and $\rho$ are non-zero. For each sign vector $r$ without zero components,

$$
\mathcal{N}^{r}=\left\{(p, q, \pi, \rho) \in \mathcal{N}: \pi_{l, s} r_{l, s}>0,(l, s) \in \check{\mathcal{L}} \times \mathcal{S}, \rho_{a} r_{a}>0, a \in \check{\mathcal{A}}\right\} .
$$

The function $\widehat{z}$ is differentiable on $\mathcal{N}^{r}$. The limit of its Jacobian, $\lim _{n \rightarrow \infty} \partial \widehat{z}$ $\left(p^{n}, q^{n}, \pi^{n}, \rho^{n}\right)=\partial \widehat{z}^{r}\left(p^{*}, q^{*}, 0,0\right)$, along a sequence $\left(\left(p^{n}, q^{n}, \pi^{n}, \rho^{n}\right) \in \mathcal{N}^{r}\right)$ that converges to $\left(p^{*}, q^{*}, 0,0\right)$, exists;

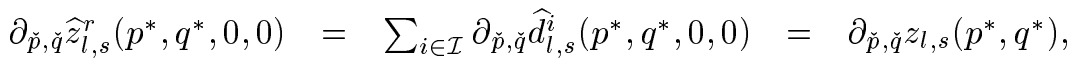

$$
\begin{aligned}
& \partial_{\check{p}, \breve{q}} \widehat{z}_{a}^{r}\left(p^{*}, q^{*}, 0,0\right)=\sum_{i \in \mathcal{I}} \partial_{\breve{p}, \breve{q}} \widehat{d}_{a}^{i}\left(p^{*}, q^{*}, 0,0\right)=\partial_{\breve{p}, \breve{q}} z_{a}\left(p^{*}, q^{*}\right),
\end{aligned}
$$

where $z(p, q)$ denotes the unconstrained total excess demand function for commodities and assets other than the numeraires at prices $(p, q)$. It follows that the Jacobian with respect to $(\check{p}, \breve{q})$ is independent of $r$ at a competitive equilibrium.

Lemma 1. If $\left(\left(p^{*}, q^{*}\right),\left(x^{*}, y^{*}\right)\right)$ is a competitive equilibrium, such that $\partial z\left(p^{*}\right.$, $\left.q^{*}\right)$ is of full rank, then, for each sign vector $r$ without zero components, the 
tangent cone at $\left(p^{*}, q^{*}\right)$ to the set of price systems having a local fix-price equilibrium with state of the markets $r$ is

$$
\begin{array}{r}
\left\{(p, q) \in \mathcal{P} \times \mathcal{Q}:(\check{p}, \breve{q})=\left(\partial z\left(p^{*}, q^{*}\right)\right)^{-1} \partial_{\pi, \rho} \widehat{z}^{r}\left(p^{*}, q^{*}, 0,0\right)(\pi, \rho),\right. \\
\left.\pi_{l, s} r_{l, s}>0,(l, s) \in \check{\mathcal{L}} \times \mathcal{S}, \rho_{a} r_{a}>0, a \in \check{\mathcal{A}}\right\} .
\end{array}
$$

Proof The restriction of $\widehat{z}$ to $\mathcal{N}^{r}$ extends to a differentiable function $\widetilde{z}: \mathcal{N} \rightarrow$ $\mathbb{R}^{L S+A}$ as follows. For $i \in \mathcal{I}$, the function $\widetilde{c}^{i}$ is defined by $\widetilde{c}_{l, s}^{i}(\pi, \rho)=\pi_{l, s}$ if $i \in \underline{\mathcal{I}}_{l, s}, r_{l, s}=-1$, or $i \in \overline{\mathcal{I}}_{l, s}, r_{l, s}=+1, \widetilde{c}_{l, s}^{i}(\pi, \rho)=0$ otherwise, and $\widetilde{c}_{a}^{i}(\pi, \rho)=\rho_{a}$ if $i \in \underline{\mathcal{I}}_{a}, r_{a}=-1$, or $i \in \overline{\mathcal{I}}_{a}, r_{a}=+1$, and $\widetilde{c}_{a}^{i}(\pi, \rho)=0$ otherwise. The function $\widetilde{z}$ is defined as $\widehat{z}$ with $c$ replaced by $\widetilde{c}$. Since $\partial z\left(p^{*}, q^{*}\right)$ is of full rank, it follows by the implicit function theorem that the solution to $\widetilde{z}(p, q, \pi, \rho)=(0,0)$ determines $p$ and $q$ as a function of $\pi$ and $\rho$ in a neighborhood of $(0,0)$. The derivative of this function at $(0,0)$ with respect to $\pi$ and $\rho$ is given by $\left(\partial z\left(p^{*}, q^{*}\right)\right)^{-1} \partial_{\pi, \rho} \widetilde{z}\left(p^{*}, q^{*}, 0,0\right)$. The expression in the proposition follows immediately if one takes into account that only $\pi$ 's and $\rho$ 's satisfying $\pi_{l, s} r_{l, s}>0,(l, s) \in \check{\mathcal{L}} \times \mathcal{S}$, and $\rho_{a} r_{a}>0, a \in \breve{\mathcal{A}}$, should be considered.

Proposition 2 in Geanakoplos and Polemarchakis (1986) shows that the assumption that $\partial z\left(p^{*}, q^{*}\right)$ has full rank at every competitive equilibrium holds generically in endowments. Lemma 3.2 characterizes the tangent cones to the regions in the price space having a fix-price equilibrium with state of the markets $r$ in the neighborhood of a competitive equilibrium. It guarantees neither that the closures of these tangent cones cover the price space nor that the tangent cones are full-dimensional nor that the tangent cones do not intersect. If this were the case, local uniqueness would result.

In general, an increase in a price causes a different individual to be rationed as a decrease in a price. Since $\partial_{\pi, \rho} \widehat{z}^{r}$, and therefore the tangent cone, depend on $\partial_{\pi, \rho} \widehat{d}^{i}$ for the individual $i$ that is rationed, the fact that the tangent cones need not fit nicely together does not come as a surprise. In abstract terms, the fact that different individuals get rationed at different prices in the neighborhood of a competitive equilibrium, creates non-differentiabilities in the function $\widehat{z}$ at competitive prices. At a point of non-differentiability, the implicit function theorem need not apply, and local uniqueness may fail.

The generalized Jacobian of a Lipschitz continuous function $f$ at a point $x$ is the convex hull of all matrices that are the limits of the sequence $\left(\partial f\left(x^{n}\right)\right)$, where $\left(x^{n}\right)$ is a convergent sequence with $\lim _{n \rightarrow \infty} x^{n}=x$ and $f$ is differentiable at $x^{n}$.

A restriction of the fundamentals of the economy, the utility functions of individuals and the matrix of asset payoffs is required to guarantee that, generically, competitive equilibrium allocations are differentiably locally unique as fix-price equilibrium allocations

If a function $f$ is Lipschitz continuous, $f(\widehat{x}, \widehat{y})=0$, and every matrix $M$ in $\partial_{x} f(\widehat{x}, \widehat{y})$ has full rank, then there exist a neighborhood $\mathcal{N}_{\widehat{x}, \widehat{y}}$, a neighborhood $\mathcal{N}_{\widehat{y}}$, and a Lipschitz continuous function $g$ on $\mathcal{N}_{\widehat{y}}$ such that $(x, y) \in \mathcal{N}_{\widehat{x}, \widehat{y}}$ and $f(x, y)=0$ if and only if $y \in \mathcal{N}_{\widehat{y}}$ and $x=g(y)$. 
Assumption 2. For endowments in $\Omega^{*}$, an open set of full Lebesgue measure, if $\left(\left(p^{*}, q^{*}\right),\left(x^{*}, y^{*}\right)\right)$ is a competitive equilibrium, then the determinants of the matrices $\partial_{\pi, \rho} \widehat{z}^{r}\left(p^{*}, q^{*}, 0,0\right)$, with $r$ sign vectors without zero components, are either all equal to -1 or all equal to +1 .

By an argument similar to the one in the proof of Theorem 1, Laroque (1981), the competitive equilibrium allocation is differentiably locally unique as a fix-price equilibrium allocation.

Remark An example of an economy that satisfies differentiable local uniqueness for all endowments and, à fortiori, satisfies Assumption 2.

There are three states of the world, two commodities and two assets. The utility functions have an additively separable representation $u^{i}=\sum_{s \in \mathcal{S}} \pi_{s} u_{s}^{i}$ with

$$
u_{s}^{i}\left(x_{s}\right)=\alpha^{i} \ln x_{1, s}+\left(1-\alpha^{i}\right) x_{2, s}, \quad 0<\alpha^{i}<1,
$$

and a uniform probability measure $\pi$ over the states of the world. The payoffs of the assets are $R_{._{1}}=(1,0,0)^{\prime}$, and $R_{._{2}}=(0,1,0)^{\prime}$. Endowments are chosen such that $\left|\underline{\mathcal{I}}_{l, s}\right|=\left|\overline{\mathcal{I}}_{l, s}\right|=1,(l, s) \in \check{\mathcal{L}} \times \mathcal{S}$, and $\left|\underline{\mathcal{I}}_{a}\right|=\left|\overline{\mathcal{I}}_{a}\right|=1, a \in \check{\mathcal{A}}$, so they belong to a set of full Lebesgue measure by Lemma 4.4 .

Competitive equilibrium prices are $\left(p^{*}, q^{*}\right)$. All partial derivatives are evaluated at $\left(p^{*}, q^{*}, 0,0\right)$. It holds that $\partial_{\pi_{1, s}} \widehat{z}^{r}=\partial_{\pi_{1, s}} \widehat{d}^{i(1, s)}$, where $\{i(1, s)\}=\underline{I}_{1, s}$ if $r_{1, s}=-1$, and $\{i(1, s)\}=\bar{I}_{1, s}$ if $r_{1, s}=+1$. An increase in $\pi_{1, s}$ corresponds to the introduction of demand rationing or the disappearance of supply rationing on commodity $(1, s)$, which decreases the demand for commodity $(1, s)$, so $\partial_{\pi_{1, s}} \widehat{z}_{1, s}^{r}$ is negative. The change in income spent on commodity $(1, s)$ equals $p_{1, s}^{*} \partial_{\pi_{1, s}} \widehat{z}_{1, s}^{r}$. The individual $i(1)$ is the one affected by rationing in the asset market, so $\{i(1)\}=\underline{I}_{1}$ if $r_{1}=-1$, and $\{i(1)\}=\bar{I}_{1}$ if $r_{1}=+1$. From the properties of the Cobb-Douglas utility function, it follows that

$$
\begin{gathered}
\partial_{\pi_{1,1}} \widehat{d}_{1,2}^{i(1,1)}=\frac{-\alpha_{1}^{i(1,1)} p_{1,1}^{*} q_{1}^{*} \partial_{\pi_{1,1}} \widehat{z}_{1,1}^{n}}{p_{1,2}^{*} q_{2}^{*}\left(2-\alpha_{1}^{i(1,1)}\right)}, \\
\partial_{\pi_{1,1}} \widehat{d}_{1,3}^{(1,1)}=0, \quad \partial_{\pi_{1,1}} \widehat{d}_{1}^{i(1,1)}=\frac{p_{1,1}^{*} \partial_{\pi_{1,1}} \widehat{z}_{1,1}^{n}}{\left(2-\alpha_{1}^{i(1,1)}\right)}, \\
\partial_{\pi_{1,2}} \widehat{d}_{1,1}^{i(1,2)}=\frac{-\alpha_{1}^{i(1,2)} p_{1,2}^{*} q_{1}^{*} \partial_{\pi_{1,2}} \widehat{z}_{1,2}^{n}}{p_{1,1}^{*} q_{2}^{*}\left(2-\alpha_{1}^{i(1,2)}\right)} \\
\partial_{\pi_{1,2}} \widehat{d}_{1,3}^{i(1,2)}=0, \quad \partial_{\pi_{1,2}} \widehat{d}_{1}^{i(1,2)}=\frac{-p_{1,2}^{*} q_{2}^{*} \partial_{\pi_{1,2}} \widehat{z}_{1,2}^{n}}{q_{1}^{*}\left(2-\alpha_{1}^{i(1,2)}\right)}, \\
\partial_{\pi_{1,3}} \widehat{d}_{1,1}^{i(1,3)}=0, \quad \partial_{\pi_{1,3}} \widehat{d}_{1,2}^{i(1,3)}=0, \quad \partial_{\pi_{1,3}} \widehat{d}_{1}^{i(1,3)}=0, \\
\partial_{\rho_{1}} \widehat{d}_{1,1}^{i(1)}=\frac{\alpha_{1}^{i(1)} \partial_{\rho_{1}} z_{1}^{n}}{p_{1,1}^{*}}, \quad \partial_{\rho_{1}} \widehat{d}_{1,2}^{i(1)}=\frac{-\alpha_{1}^{i(1)} q_{1}^{*} \partial_{\rho 1} \widehat{z}_{1}^{n}}{p_{1,2}^{*} q_{2}^{*}}, \quad \partial_{\rho_{1}} \widehat{d}_{1,3}^{i(1)}=0 .
\end{gathered}
$$

The sign of the determinant of $\partial_{\pi, \rho} \widehat{z}^{r}$ does not change by premultiplying it by the strictly positive row vector $\left(p_{1,1}^{*} q_{1}^{*}, p_{1,2}^{*} q_{2}^{*}, 1, q_{1}^{*}\right)$ and postmultiplying it by 
the strictly positive column vector $\left(\left(2-\alpha_{1}^{i(1,1)}\right) /-p_{1,1}^{*} q_{1}^{*} \partial_{\pi_{1,1}} \widehat{z}_{1,1}^{r},\left(2-\alpha_{1}^{i(1,2)}\right) /-\right.$ $\left.p_{1,2}^{*} q_{2}^{*} \partial_{\pi_{1,2}} \widehat{z}_{1,2}^{r}, 1 /-\widehat{z}_{1,3}^{r}, 1 /-q_{1}^{*} \partial_{\rho_{1} \widehat{z}_{1}^{r}}\right)^{\prime}$. The resulting matrix is given by

$$
\left[\begin{array}{cccc}
\alpha_{1}^{i(1,1)}-2 & \alpha_{1}^{i(1,2)} & 0 & -\alpha_{1}^{i(1)} \\
\alpha_{1}^{i(1,1)} & \alpha_{2}^{i(1,2)}-2 & 0 & \alpha_{1}^{i(1)} \\
0 & 0 & -1 & 0 \\
-1 & 1 & 0 & -1
\end{array}\right]
$$

and its determinant equals

$$
\left(4-2 \alpha_{1}^{i(1,1)}-2 \alpha_{1}^{i(1,2)}\right)\left(1-\alpha_{1}^{i(1)}\right)>0 .
$$

The determinant of $\partial_{\pi, \rho} \widehat{z}^{r}$ is positive, irrespective of the sign vector $r$. It follows that the competitive equilibrium allocation is differentiably locally unique as a fix-price equilibrium allocation.

As in Laroque (1981), whenever there are two sign vectors without zero components $r^{1}$ and $r^{2}$ such that the determinants of $\partial_{\pi, \rho} \widehat{z}^{r^{1}}\left(p^{*}, q^{*}, 0,0\right)$ and $\partial_{\pi, \rho} \widehat{z}^{r^{2}}\left(p^{*}, q^{*}, 0,0\right)$ have opposite signs and $\partial z\left(p^{*}, q^{*}\right)$ has full rank, then for every neighborhood $\mathcal{N}_{x^{*}, y^{*}}$ there exists for every neighborhood $\mathcal{N}_{p^{*}, q^{*}}$ a price system $(p, q) \in \mathcal{N}_{p^{*}, q^{*}}$ with at least two fix-price equilibrium allocations in $\mathcal{N}_{x^{*}, y^{*}}$. Assumption 2 is "almost necessary" for the differentiable local uniqueness of competitive equilibrium allocations.

Local uniqueness of fix-price equilibrium allocations at competitive equilibria is not too strong a requirement. It is less demanding than the requirement of uniqueness of fix-price equilibrium allocations at prices in a neighborhood of competitive prices. The latter requirement guarantees a certain degree of generality of our results.

The function $(\widehat{x}, \widehat{y}): \mathcal{N}_{p^{*}, q^{*}} \rightarrow \mathbb{R}^{I(L+1) S+I(A+1)}$ associates the unique fixprice equilibrium allocation in $\mathcal{N}_{x^{*}, y^{*}}$ to $(p, q) \in \mathcal{N}_{p^{*}, q^{*}}$. The indirect utility function of an individual at a locally unique fix-price equilibrium is defined by

$$
v^{i}(p, q)=u^{i}\left(\widehat{x}^{i}(p, q)\right), \quad(p, q) \in \mathcal{N}_{p^{*}, q^{*}} .
$$

Lemma 2. If $\left(\left(p^{*}, q^{*}\right),\left(x^{*}, y^{*}\right)\right)$ is a competitive equilibrium, then the indirect utility function $v^{i}: \mathcal{N}_{p^{*}, q^{*}} \rightarrow \mathbb{R}$ is differentiable and

$$
\partial_{p_{l, s}} v^{i}\left(p^{*}, q^{*}\right)=-\partial_{x_{L+1, s}} u^{i}\left(x^{i *}\right)\left(x_{l, s}^{i *}-e_{l, s}^{i}\right), \quad(l, s) \in \breve{\mathcal{L}} \times \mathcal{S} .
$$

Proof For every sign vector $r$, the restriction of $v^{i}$ to $\mathcal{N}_{p^{*}, q^{*}} \cap \mathcal{P} \mathcal{Q}(r)$, denoted $v^{i^{r}}$, is differentiable. From the differentiation of the budget constraints

$$
q \widehat{y}^{i^{r}}(p, q)=0 \text { and } p_{s}\left(\widehat{x}_{s}^{i^{r}}(p, q)-e_{s}^{i}\right)=R_{s} \cdot \widehat{y}^{i^{r}}(p, q), \quad s \in \mathcal{S}
$$


with respect to $p_{\bar{l}, \bar{s}}$, and the first order conditions for individual optimization at a competitive equilibrium,

$$
\partial_{x_{l, s}^{i}} u^{i}\left(x^{i *}\right)=\partial_{x_{L+1, s}^{i}} u^{i}\left(x^{i *}\right) p_{l, s}^{*}, \quad(l, s) \in \check{\mathcal{L}} \times \mathcal{S},
$$

and

$$
\sum_{s \in \mathcal{S}} \partial_{x_{L+1, s}^{i}} u^{i}\left(x^{i *}\right) R_{s}=\mu^{i} q^{*}, \quad \text { for some } \mu^{i}>0,
$$

it follows that

$$
\partial_{p_{\bar{l}, \bar{s}}} v^{i^{r}}\left(p^{*}, q^{*}\right)=-\partial_{x_{L+1, \bar{s}}^{i}} u^{i}\left(x^{i *}\right)\left(x_{\bar{l}, \bar{s}}^{i *}-e_{\bar{l}, \bar{s}}^{i}\right) .
$$

Since the derivative is independent of the sign vector $r$, the result follows.

\section{Appendix 3: Pareto improving price regulation}

Price regulation can Pareto improve on a competitive equilibrium $\left(\left(p^{*}, q^{*}\right)\right.$, $\left.\left(x^{*}, y^{*}\right)\right)$ if there exist prices of commodities $p$ such that a fix-price equilibrium of commodities at prices of commodities and assets $\left(p, q^{*}\right)$ Pareto dominates the allocation $x^{*}$. The ambiguity introduced by the possibility of multiple fix-price equilibrium allocations at prices $\left(p, q^{*}\right)$ is circumvented by considering local variations at competitive equilibrium allocations that are differentiably locally unique as fix-price equilibria.

Pareto improvement by price regulation is possible only if the asset market is incomplete. Another necessary requirement is that the economy allows for heterogeneous individuals.

Assumption 3. $A+1<S$ and $I>1$.

The function $\varphi$ is defined by

$$
\varphi(x, \widetilde{\lambda}, \widetilde{p}, e)=\left(\begin{array}{l}
\partial u^{i}\left(x^{i}\right)-\widetilde{\lambda}^{i} \widetilde{p}, \quad i \in \mathcal{I} \\
\sum_{s \in \mathcal{S}} \widetilde{p}_{s}\left(x_{s}^{i}-e_{s}^{i}\right), \quad i \in \mathcal{I} \\
\sum_{i \in \mathcal{I}}\left(x_{l, s}^{i}-e_{l, s}^{i}\right), \quad(l, s) \in \mathcal{L} \times \mathcal{S} \backslash\{(L+1, S)\} \\
\sum_{s \in \mathcal{S}} n_{s} \widetilde{p}_{s}\left(x_{s}^{i}-e_{s}^{i}\right), \quad i \in \mathcal{I} \backslash\{1\}
\end{array}\right),
$$

where the Lagrangian multiplier $\widetilde{\lambda}^{i} \in \mathbb{R}$ does not vary with the state of the world, the prices of commodities $\widetilde{p} \in \mathbb{R}_{++}^{(L+1) S-1} \times\{1\}$ are discounted prices, with only the price of commodity $(L+1, S)$ normalized to 1 , and $n \neq 0$ is a fixed vector such that $n R=0$. In the standard reformulation of the incomplete markets model in discounted prices, it is assumed that one individual is unconstrained, so that his marginal utility at an optimal choice is proportional to the price 
system. Pareto optimality implies that the marginal utility vectors of all agents should be proportional to the price system. The function $\varphi$ is completed by specifying budget constraints and market clearing conditions, and one condition for every individual but one that recognizes the incompleteness of markets: $\sum_{s \in \mathcal{S}} n_{s} \widetilde{p}_{s}\left(x_{s}^{i}-e_{s}^{i}\right)=0$. The existence of $n \neq 0$ such that $n R=0$ follows from market incompleteness. It follows that the function $\varphi$ vanishes at a Pareto optimal competitive equilibrium.

For a function $f$ that depends on a vector of variables $\alpha$ and on endowments $e, f_{e}(\alpha)$ is the function that results from fixing $e$; for instance, $\varphi_{e}(x, \widetilde{\lambda}, \widetilde{p})=$ $\varphi(x, \widetilde{\lambda}, \widetilde{p}, e)$.

Lemma 3. Generically, competitive equilibrium allocations are not Pareto optimal.

Proof A necessary condition for $x$ to be a Pareto optimal competitive equilibrium allocation for an economy $e$ is that $\varphi_{e}(x, \widetilde{\lambda}, \widetilde{p})=0$. Since the dimension of the domain of $\varphi_{e}$ is lower than the dimension of the range, whenever $\varphi_{e}$ is transverse to 0 , a solution to $\varphi_{e}(x, \widetilde{\lambda}, \widetilde{p})=0$ does not exist. By a standard argument, $\varphi$ is transverse to 0 . By the transversal density theorem, the set of economies for which $\varphi_{e}$ is transverse to 0 has full Lebesgue measure. By a standard argument, this set can be chosen to be open.

The function $\psi: \Xi \times \Omega^{*} \rightarrow \mathbb{R}^{N}$ is defined by

$$
\psi(\xi, e)=\left(\begin{array}{l}
\partial_{x_{s}^{i}} u^{i}\left(x^{i}\right)-\lambda_{s}^{i} p_{s}, \quad i \in \mathcal{I}, s \in \mathcal{S} \\
p_{s}\left(x_{s}^{i}-e_{s}^{i}\right)-R_{s} . y^{i}, \quad i \in \mathcal{I}, s \in \mathcal{S} \\
\lambda^{i} R-\mu^{i} q, \quad i \in \mathcal{I} \\
\sum_{i \in \mathcal{I}}\left(x_{l, s}^{i}-e_{l, s}^{i}\right), \quad(l, s) \in \check{\mathcal{L}} \times \mathcal{S} \\
\sum_{i \in \mathcal{I}} y_{a}^{i}, \quad a \in \check{\mathcal{A}} \\
q y^{i}, \quad i \in \mathcal{I}
\end{array}\right),
$$

$\xi=(x, \lambda, y, \mu, \check{p}, \check{q})$ and $\Xi=\mathbb{R}_{++}^{I(L+1) S} \times \mathbb{R}_{++}^{I S} \times \mathbb{R}^{I(A+1)} \times \mathbb{R}^{I} \times \check{P} \times \check{Q}$. The dimension of $\Xi$ is $N$. When $\xi^{*}$ is consistent with a competitive equilibrium, it is necessarily the case that $\psi_{e}\left(\xi^{*}\right)=0$.

The function $h: \Xi \times \mathbb{R}^{I} \times \Omega^{*} \rightarrow \mathbb{R}^{L S+1}$ is defined by

$$
h(\xi, \alpha, e)=\left(\begin{array}{ll}
\sum_{i \in \mathcal{I}} \alpha^{i} \lambda_{s}^{i}\left(x_{l, s}^{i}-e_{l, s}^{i}\right), \quad(l, s) \in \check{\mathcal{L}} \times \mathcal{S} \\
\sum_{i \in \mathcal{I}}\left(\alpha^{i}\right)^{2}-1
\end{array}\right) .
$$

A competitive equilibrium can be Pareto improved by price regulation if the matrix of partial derivatives of the indirect utility functions with respect to 
prices has full rank ${ }^{4}$. By Proposition 4.8, this matrix is guaranteed to have full rank if there is no solution to $\psi_{e}(\xi)=0$ in combination with $h_{e}(\xi, \alpha)=0$.

The function $\widetilde{\psi}: \Xi \times \mathbb{R}^{I} \times \Omega^{*} \rightarrow \mathbb{R}^{N+L S+1}$ is defined by

$$
\widetilde{\psi}(\xi, \alpha, e)=\left(\begin{array}{c}
\psi(\xi, e) \\
h(\xi, \alpha, e)
\end{array}\right) .
$$

If $\widetilde{\psi}$ is transverse to 0 , then it follows from the transversal density theorem that for a subset of endowments of full Lebesgue measure, $\widetilde{\psi}_{e}$ is transverse to 0 . If $L S \geq I$, then the dimension of the range of $\widetilde{\psi}_{e}$ exceeds that of the domain. Transversality of $\widetilde{\psi}_{e}$ implies that there are no solutions to the associated system of equations. It is possible to Pareto improve all competitive equilibria by price regulation.

Proposition 1. If $L S \geq I$, then, generically, all competitive equilibria of $\mathcal{E}$ can be Pareto improved by price regulation.

Proof One fixes $(\bar{l}, \bar{s}) \in \check{\mathcal{L}} \times \mathcal{S}$ and $\Omega^{* *}$, an open subset of endowments in $\Omega^{*}$ of full Lebesgue measure, such that no competitive equilibrium of the associated economy $\mathcal{E}$ is Pareto optimal. The function $\widehat{\psi}: \Xi \times \Omega^{* *} \rightarrow \mathbb{R}^{N+1}$ is defined by

$$
\widehat{\psi}(\xi, e)=\left(\begin{array}{l}
\psi(\xi, e) \\
\sum_{s \in \mathcal{S} \backslash\{\bar{s}\}} \sum_{i \in \mathcal{I}} \frac{\lambda_{\lambda_{s}^{s}}^{i}}{s}\left(x_{\bar{l}, s}^{i}-e_{\bar{l}, s}^{i}\right)
\end{array}\right) .
$$

If $\widehat{\psi}(\xi, e)=0$, then the matrix $\widehat{M}$ of partial derivatives of $\widehat{\psi}$ evaluated at $(\xi, e)$ has full row rank: if $v^{\prime} \widehat{M}=0$, then $v=0$. The components of $v$ are $v_{1, i, l, s}, i \in \mathcal{I}$, $(l, s) \in \mathcal{L} \times \mathcal{S}, v_{2, i, s}, i \in \mathcal{I}, s \in \mathcal{S}, v_{3, i, a}, i \in \mathcal{I}, a \in \mathcal{A}, v_{4, l, s},(l, s) \in \mathcal{L} \times \mathcal{S}, v_{5, a}$, $a \in \mathcal{A}, v_{6, i}, i \in \mathcal{I}$, and $v_{9}$, according to the labelling of the equations defining $\widehat{\psi}$.

If $v$ is such that $v^{\prime} \widehat{M}=0$, then $0=v^{\prime} \partial_{e_{L+1, s}^{i}} \widehat{\psi}(\xi, e)=-v_{2, i, s}, i \in \mathcal{I}, s \in \mathcal{S}$. It follows that, for $i \in \mathcal{I}$,

$$
\begin{aligned}
& 0=v^{\prime} \partial_{e_{l, s}^{i}} \widehat{\psi}(\xi, e)=-v_{4, l, s}, \quad(l, s) \in(\check{\mathcal{L}} \backslash\{\bar{l}\}) \times \mathcal{S}, \\
& 0=v^{\prime} \partial_{e_{\bar{l}, s}^{i}} \widehat{\psi}(\xi, e)=-v_{4, \bar{l}, s}-v_{9} \frac{\lambda_{s}^{i}}{\lambda_{s}^{i}}=0, \quad s \in \mathcal{S} \backslash\{\bar{s}\}, \\
& 0=v^{\prime} \partial_{e_{\bar{l}, s}^{i}} \widehat{\psi}(\xi, e)=-v_{4, \bar{l}, \bar{s}} .
\end{aligned}
$$

Consequently, if $v_{4, \bar{l}, \widehat{s}}=0$ for some $\widehat{s} \in \mathcal{S} \backslash\{\bar{s}\}$, then $v_{9}=0$ and $v_{4, \bar{l}, s}=0$, for all $s \in \mathcal{S} \backslash\{\bar{s}\}$. If, on the contrary, $v_{4, \bar{l}, s} \neq 0$, for all $s \in \mathcal{S} \backslash\{\widehat{s}\}$, then

$$
\frac{\lambda_{s}^{i}}{\lambda_{\bar{s}}^{i}}=-\frac{v_{4, \bar{l}, s}}{v_{9}}=\frac{\lambda_{s}^{i^{\prime}}}{\lambda_{\bar{s}}^{i^{\prime}}}, \quad i, i^{\prime} \in \mathcal{I}, s \in \mathcal{S} \backslash\{\bar{s}\} .
$$

\footnotetext{
${ }^{4}$ If the matrix of partial derivatives has full rank, it is possible to generate any desired marginal change in utilities by means of price regulation.
} 
Hence, for $i, i^{\prime} \in \mathcal{I}$, for $s^{1}, s^{2} \in \mathcal{S}, \lambda_{s^{1}}^{i} / \lambda_{s^{2}}^{i}=\left(\lambda_{s^{1}}^{i} / \lambda_{s}^{i}\right)\left(\lambda_{s}^{i} / \lambda_{s^{2}}^{i}\right)=\left(\lambda_{s^{1}}^{i^{\prime}} / \lambda_{s}^{i^{\prime}}\right)\left(\lambda_{s}^{i^{\prime}} /\right.$ $\left.\lambda_{s^{2}}^{i^{\prime}}\right)=\lambda_{s^{1}}^{i^{\prime}} / \lambda_{s^{2}}^{i^{\prime}}$. The economy $e$ has then a Pareto optimal competitive equilibrium induced by $\xi$, contradicting $e \in \Omega^{* *}$. Consequently, $v_{4, \bar{l}, s}=0, s \in \mathcal{S} \backslash\{\bar{s}\}$, and $v_{9}=0$.

For $i \in \mathcal{I}$, and $(l, s) \in \mathcal{L} \times \mathcal{S}$,

$$
0=v^{\prime} \partial_{x_{l, s}^{i}} \widehat{\psi}(\xi, e)=v_{1, i, \cdot,}^{\prime} \partial_{x_{l, s}^{i}} \partial u^{i}\left(x^{i}\right) .
$$

It is possible to represent a utility function satisfying A2 by one with $\partial^{2} u^{i}\left(x^{i}\right)$ negative definite on a bounded subset of the consumption set. Then it follows that $v_{1, i, \cdot,}=0$. For $i \in \mathcal{I}, 0=v^{\prime} \partial_{y_{A+1}^{i}} \widehat{\psi}(\xi, e)=v_{8, i}$. Also, for $a \in \check{\mathcal{A}}, 0=$ $v^{\prime} \partial_{y_{a}^{i}} \widehat{\psi}(\xi, e)=v_{5, a}$. Finally, $0=v^{\prime} \partial_{\lambda_{s}^{i}} \widehat{\psi}(\xi, e)=v_{3, i,}^{\prime}, R_{s}^{\prime}, i \in \mathcal{I}, s \in \mathcal{S}$. Since $R$ has full column rank it follows that $v_{3, i, a}=0, i \in \mathcal{I}, a \in \mathcal{A}$.

Therefore, $v=0, \widehat{M}$ has full row rank $N+1$, and $\widehat{\psi}$ is transverse to 0 . The set of endowments such that $\widehat{\psi}_{e}$ is transverse to zero is denoted $\widehat{\Omega}_{\bar{l}, \bar{s}}$. By the transversal density proposition, $\Omega^{* *} \backslash \widehat{\Omega}_{\bar{l}, \bar{s}}$ has Lebesgue measure zero. For $e \in \widehat{\Omega}_{\bar{l}, \bar{s}}$, the dimension of the range of $\widehat{\psi}_{e}$ exceeds that of the domain, so $\left(\widehat{\psi}_{e}\right)^{-1}(\{0\})=\emptyset$.

The set $\widehat{\Omega}=\cap_{(l, s) \in \check{\mathcal{L}} \times \mathcal{S}} \widehat{\Omega}_{l, s}$ is of full Lebesgue measure and, by a standard argument, open. Redefine the function $\widetilde{\psi}$ such that endowments belong to $\Omega^{*} \cap \widehat{\Omega}$. For $(\xi, \alpha, e)$ such that $\widetilde{\psi}(\xi, \alpha, e)=0, \widetilde{M}$ is the matrix of partial derivatives of $\widetilde{\psi}$ evaluated at $(\xi, \alpha, e)$.

If $v$ is such that $v^{\prime} \widetilde{M}=0$, and the components of $v$ are denoted by $v_{1, i, l, s}$, $v_{2, i, s}, v_{3, i, a}, v_{4, l, s}, v_{5, a}, v_{6, i}, v_{7, l, s}$, and $v_{8}$, then, $0=v^{\prime} \partial_{e_{L+1, s}^{i}} \widetilde{\psi}(\xi, \alpha, e)=-v_{2, i, s}$, $i \in \mathcal{I}, s \in \mathcal{S}$. Hence,

$$
0=v^{\prime} \partial_{e_{l, s}^{i}} \widetilde{\psi}(\xi, \alpha, e)=-v_{4, l, s}-\alpha^{i} \lambda_{s}^{i} v_{7, l, s}, \quad i \in \mathcal{I},(l, s) \in \check{\mathcal{L}} \times \mathcal{S} .
$$

Since $\sum_{i \in \mathcal{I}}\left(\alpha^{i}\right)^{2}=1$, there is $i^{\prime}$ such that $\alpha^{i^{\prime}} \neq 0$. If there is $\bar{s} \in \mathcal{S}$ such that, for $i \in \mathcal{I} \backslash\left\{i^{\prime}\right\}, \alpha^{i^{\prime}} \lambda \frac{i^{\prime}}{s}-\alpha^{i} \lambda \frac{i}{s}=0$, then, for any $l \in \check{\mathcal{L}}$,

$$
\begin{aligned}
0 & =\sum_{s \in \mathcal{S} \backslash\{\bar{s}\}} \sum_{i \in \mathcal{I}} \alpha^{i} \lambda_{s}^{i}\left(x_{l, s}^{i}-e_{l, s}^{i}\right)=\sum_{s \in \mathcal{S} \backslash\{\bar{s}\}} \sum_{i \in \mathcal{I}} \frac{\alpha^{i^{i^{\prime}}}}{\lambda_{\frac{1}{s}}^{i}} \lambda_{s}^{i}\left(x_{l, s}^{i}-e_{l, s}^{i}\right) \\
& =\alpha^{i^{\prime}} \lambda_{\bar{s}}^{i^{\prime}} \sum_{s \in \mathcal{S} \backslash\{\bar{s}\}} \sum_{i \in \mathcal{I}} \frac{\lambda_{s}^{i}}{\lambda_{\bar{s}}^{i}}\left(x_{l, s}^{i}-e_{l, s}^{i}\right) .
\end{aligned}
$$

Since $\alpha^{i^{i}} \neq 0, \sum_{s \in \mathcal{S} \backslash\{\bar{s}\}} \sum_{i \in \mathcal{I}}\left(\lambda_{s}^{i} / \lambda_{\bar{s}}^{i}\right)\left(x_{l, s}^{i}-e_{l, s}^{i}\right)=0$, a contradiction since $e \in$ $\widehat{\Omega}$. Consequently, for every $s \in \mathcal{S}$, there is $i \in \mathcal{I} \backslash\left\{i^{\prime}\right\}$ such that $\alpha^{i^{\prime}} \lambda_{s}^{i^{\prime}}-\alpha^{i} \lambda_{s}^{i} \neq 0$. For $(l, s) \in \check{\mathcal{L}} \times \mathcal{S},\left(\alpha^{i^{\prime}} \lambda_{s}^{i^{\prime}}-\alpha^{i} \lambda_{s}^{i}\right) v_{7, l, s}=0$, so $v_{7, l, s}=0$, and, thus $v_{4, l, s}=0$. Also, $0=v^{\prime} \partial_{\alpha^{i^{\prime}}} \widetilde{\psi}(\xi, \alpha, e)=2 \alpha^{i^{\prime}} v_{8}$, so, since $\alpha^{i^{\prime}} \neq 0, v_{8}=0$. It follows as in the first part of the proof that $v_{1, i, l, s}=0, i \in \mathcal{I},(l, s) \in \check{\mathcal{L}} \times \mathcal{S}$, that $v_{6, i}=0, i \in \mathcal{I}$, that $v_{5, a}=0, a \in \check{\mathcal{A}}$, and that $v_{3, i, a}=0, i \in \mathcal{I}, a \in \mathcal{A}$.

Therefore, $\widetilde{M}$ has rank $N+L S+\_1$ and $\widetilde{\psi}$ intersects 0 transversally. If $\widetilde{\Omega}$ is the set of economies such that $\widetilde{\psi}_{e}$ is transverse to 0 , then $\Omega^{*} \backslash \widetilde{\Omega}$ has 
Lebesgue measure zero by the transversal density theorem. Openness follows by a standard argument.

Generically, it is possible to make every individual better off by choosing appropriate price regulations on the spot markets when asset markets are incomplete. One needs at least as many instruments, $L S$, as individuals, $I$. Proposition 1 makes clear that this is all one needs. This is not the case in the constrained suboptimality result of Geanakoplos and Polemarchakis (1986), which applies when $2 L \leq I \leq L(S-1)+1$.

A competitive equilibrium can be Pareto improved by uniform price regulation if the matrix of partial derivatives of the indirect utility functions with respect to uniform price regulation has full rank.

The function $k: \Xi \times \mathbb{R}^{I} \times \Omega^{*} \rightarrow \mathbb{R}^{L+1}$ is defined by

$$
k(\xi, \alpha, e)=\left(\begin{array}{l}
\sum_{s \in \mathcal{S}} h_{l, s}(x, \lambda, \alpha, e), \quad l \in \breve{\mathcal{L}} \\
\sum_{i \in \mathcal{I}}\left(\alpha^{i}\right)^{2}-1
\end{array}\right) .
$$

The matrix of partial derivatives of the indirect utility functions with respect to uniform price regulation is guaranteed to have full rank if there is no solution to $\psi_{e}(\xi)=0$ in combination with $k_{e}(\xi, \alpha)=0$.

Corollary 1. If $L \geq I$, then, generically, all competitive equilibria of $\mathcal{E}$ can be Pareto improved by uniform price regulation.

Proof The argument follows that in the proof of Proposition 5.3. The equations related to $h$ that characterize Pareto improving price regulation are replaced by the equations related to $k$ that characterize Pareto improvements by uniform price regulation. This defines a function $\bar{\psi}$. The matrix $\bar{M}$ gives the partial derivatives of $\bar{\psi}$ evaluated at some $(\xi, \alpha, e)$ with $\bar{\psi}(\xi, \alpha, e)=0$. If $v^{\prime} \bar{M}=0$, by considering the partial derivatives with respect to $e_{l, s}^{i}$, it follows that $v_{2, i, s}=0, i \in \mathcal{I}, s \in \mathcal{S}$, and $v_{4, l, s}+\alpha^{i} \lambda_{s}^{i} v_{7, l}=0, i \in \mathcal{I},(l, s) \in \check{\mathcal{L}} \times \mathcal{S}$. If $i^{\prime}$ is such that $\alpha^{i^{\prime}} \neq 0$, and if $\bar{s} \in \mathcal{S}$ such that, for $i \in \mathcal{I} \backslash\left\{i^{\prime}\right\}, \alpha^{i^{\prime}} \lambda \frac{i^{\prime}}{s}-\alpha^{i} \lambda \frac{i}{s}=0$, then

$$
\begin{aligned}
0 & =\sum_{i \in \mathcal{I}} \alpha^{i} \sum_{s \in \mathcal{S}} \lambda_{s}^{i}\left(x_{l, s}^{i}-e_{l, s}^{i}\right)=\alpha^{i^{\prime}} \lambda_{\frac{i^{\prime}}{s}} \sum_{i \in \mathcal{I}} \sum_{s \in \mathcal{S}} \frac{\lambda_{s}^{i}}{\lambda_{s}^{i}}\left(x_{l, s}^{i}-e_{l, s}^{i}\right) \\
& =\sum_{i \in \mathcal{I}} \sum_{s \in \mathcal{S}} \frac{\lambda_{s}^{i}}{\lambda_{s}^{i}}\left(x_{l, s}^{i}-e_{l, s}^{i}\right)=\sum_{i \in \mathcal{I}} \sum_{s \in \mathcal{S} \backslash\{\bar{s}\}} \frac{\lambda_{s}^{i}}{\lambda_{s}^{i}}\left(x_{l, s}^{i}-e_{l, s}^{i}\right), \quad l \in \check{\mathcal{L}},
\end{aligned}
$$

which contradicts $e \in \widehat{\Omega}$. It follows that $v_{4, l, s}=0,(l, s) \in \check{\mathcal{L}} \times \mathcal{S}$, and $v_{7, l}=0, l \in$ $\breve{\mathcal{L}}$. The remainder of the proof follows the argument in the proof of Proposition 6. 